\title{
Nas malhas do império: história, literatura, mulheres e exclusão
}

\author{
Margarida Calafate Ribeiro \\ Universidade de Coimbra
}

RESUMO: ESTE ARTIGO PARTE DO TEMA LITERATURA E EXCLUSÃO PARA ANALISAR A LONGA EXCLUSÃO DAS MULHERES COMO SUJEITOS HISTÓRICOS NA HISTÓRIA PORTUGUESA E OS SEUS REFLEXOS NA LITERATURA. NO ARTIGO É FEITA UMA ANÁLISE SUMÁRIA DESSA SITUAÇÃO NA LITERATURA, COM ESPECIAL LEITURA DA LITERATURA CONTEMPORÂNEA E EM PARTICULAR DE NOVAS CARTAS PORTUGUESAS, DE MARIA ISABEL BARRENO, MARIA VELHO DA COSTA E MARIA TERESA HORTA, E DA PINTURA DE PAULA REGO, EM QUE SE DENUNCIA A DISCRIMINAÇÃO, AO MESMO TEMPO EM QUE SE ASSINALA A RUPTURA DE UMA SITUAÇÃO COM A ESPESSURA DE SÉCULOS.

ABSTRACT: THIS PAPER FRAMES AN ANALYSIS OF THE LONG LASTING ABSENCE OF WOMEN AS HISTORICAL SUBJECTS IN PORTUGUESE HISTORY AND ITS REFLEXES IN LITERATURE WITHIN THE THEME OF LITERATURE AND EXCLUSION. THE PAPER CARRIES OUT A SUMMARY ANALYSIS OF THIS SITUATION THROUGH A READING OF CONTEMPORARY LITERATURE, IN PARTICULAR OF NOVAS CARTAS PORTUGUESAS, BY MARIA ISABEL BARRENO, MARIA VELHO DA COSTA AND MARIA TERESA HORTA, AND OF PAINTINGS BY PAULA REGO. HERE, SUCH DISCRIMINATION IS DENOUNCED WHILE A RUPTURE WITH A CENTURIES OLD SITUATION IS HIGHLIGHTED.

PALAVRAS-CHAVE: LITERATURA - EXCLUSÃO - HISTÓRIA - MULHERES KEY-WORDS: LITERATURE - EXCLUSION - HISTORY - WOMEN 


\section{I - A Abrir}

tema que anima este número, Literatura, cultura e exclusão, abre um sem-número de pistas na análise da literatura portuguesa, levantando de imediato o questionamento relativo ao tão discutido cânone consagrado das histórias da literatura tradicionais. Se é certo que Portugal, devido à longa ditadura que viveu ao longo de quase 50 anos do século XX, teve no ensino da literatura e na concepção das histórias literárias ou dos manuais de literatura e de história, um forte instrumento para "desenvolver o sentimento nacional e a formação moral do aluno", como se dizia na legislação do Ministério da Educação Nacional de então", também é certo e quase paradoxal que uma das mais importantes histórias da literatura, História da Literatura Portuguesa, ainda hoje referencial, tenha sido feita por dois oposicionistas ao regime, Óscar Lopes e António José Saraiva. Publicada pela primeira vez em 1953 e re-publicada inúmeras vezes em edições revistas ao longo de cinco décadas, a História da Literatura Portuguesa tornou-se o instrumento de estudo e análise do imaginário literário português para gerações de portugueses. No entanto, esta História da Literatura Portuguesa, nas suas sucessivas reedições revistas, não reflecte as grandes questões que se começaram a colocar ao objecto literário a partir da década de 1960, preferindo antes (e provavelmente acertadamente, dada a situação política do país) continuar a apostar num modelo cronológico, de matriz positivista. Todavia, problematiza os períodos literários, e inclui e reflecte sobre grandes escritores que, numa visão mais apertada e esclarecida da censura que o regime exercia, poderiam ser considerados potencialmente subversivos e, portanto, excluídos do cânone, que, por inclusão e exclusão, qualquer história da literatura constrói ${ }^{2}$. Talvez essa versatilidade prática desta História da Literatura Portuguesa explique, por um lado, o facto de apesar das grandes mudanças, trazidas pela revolução de 25 de

1 SILVA, Maria Regina Tavares da. A mulber-bibliografia anotada 1598-1998. Lisboa: Cosmos, 1999. WALIA, Shelley. Edward Said y la historiografia. Barcelona: Gedisa, 2004. Decreto-lei 27084 de 14 de outubro de 1936, citado por Teresa Seruya e Maria Lin Sousa Moniz, "História literária e traduções no Estado Novo. Uma introdução possível”, in: IV Congresso Internacional da Associação Portuguesa de Literatura Comparada. Disponível em:

$<$ http://www.eventos.uevora.pt/comparada/VolumeII/HISTORIALITERARIAETRADUCOESNOESTADONOVO.pdf $>$. Acedido a 15 de agosto de 2007.

2 Ver ZILBERMAN, Regina. "Discursos e Marginalidade", Banco de Dados Literários, org. César Giusti. Catalogação: BDL: CUL-4-008. 
Abril de 1974, nomeadamente no ensino, esta História da Literatura Portuguesa se mantenha, sem grandes questionamentos, como uma referência nacional, e por outro lado, explique também algum atraso, outras vezes retracção, de Portugal em abordar as questões que no campo da literatura e da teoria literária começaram a ser formuladas no final dos anos 1960, levando à subsequente desestabilização e problematização do cânone.

A partir do final dos anos 1960, princípio dos anos 1970, mercê das grandes transformações políticas, geopolíticas, sociais e culturais - a descolonização, primeiro na Ásia, depois em África, os movimentos sociais da América Latina, os feminismos, as lutas pelos direitos civis dos negros na América do Norte e tantas outras convulsões -, o mundo abre-se à pluralidade ${ }^{3}$ e os grandes questionamentos teóricos impõem-se. Na literatura, na historiografia, na sociologia, e nas ciências sociais e humanas em geral começa-se a questionar, primeiro de forma dispersa e depois de maneira sucessivamente mais sistematizada, sobre tudo o que os "cânones" das várias disciplinas tinham deixado de fora. Assim começaram a surgir dentro da Europa, mas principalmente fora dela, os pensadores alternativos, movidos pelo interesse em saber o que havia para além dos "cânones". Relativamente à literatura podemos dizer mesmo que, para além do questionamento das histórias da literatura excessivamente eurocentradas, tratava-se da mutação do próprio objecto de estudo da literatura, numa linha aliás próxima do que na historiografia se veio a designar como "nova história", em que, como assinala Le Goff, se lança o questionamento não só sobre as perspectivas e o modo de narrar a história, mas sobre o próprio objecto de estudo da história, ou melhor, sobre a pluralidade de objectos de estudos ${ }^{4}$ que o estudo da história e, por extensão, da literatura, envolveria: assim surge a atenção para a literatura escrita por mulheres, o reconhecimento de uma literatura feminista, a literatura de cordel, a história dos homens e mulheres comuns e dos seus quotidianos contra uma história feita de heróis, reis e feitos militares, mas surgem também as novas textualidades ou textualidades emergentes, que levaram Antonio Candido a falar de "textos indefiníveis": "Romances que parecem reportagens, contos que não se dis-

3 Ver PIZARRO, Ana. "Delinear a história literária hoje?", in: O Sul e os Trópicos - ensaios de cultura latino-americana. Niterói: EDUFF, 2006, p. 26.

4 Idem, ibidem, p. 28. 
tinguem de poemas ou crônicas [...] autobiografias com tonalidade e técnica de romance; [...] textos feitos com justaposição de recortes, documentos, reflexões de todo o tipo" (CANDIDO, 1995: 310). Resumidamente, iniciava-se aqui a grande mutação na análise e na perspectiva de considerar o fenómeno literário, começando justamente por estudar e questionar tudo aquilo que o cânone consagrado, representado nas histórias da literatura, tinha deixado de fora, ou, por outras palavras, tinha excluído. E podemos mesmo dizer, com Regina Zilberman, que "a reflexão sobre o que se deixou de fora tem sido matéria da história da literatura nos dias de hoje" ${ }^{\text {, }}$, como demonstra bem o tema do número desta revista.

Nos anos 1980, com o advento dos estudos pós-coloniais, inspirados pelo pronunciamento crítico lançado por Edward Said e de outras vozes vindas também de outras periferias culturais, a reflexão crítica intensifica-se e espalha-se aos mais variados campos do conhecimento, procurando desta vez a história, a palavra e o rosto de todos aqueles sujeitos e produtores de cultura que ficaram excluídos da história do Ocidente, aquele que até então detinha o poder de narrar a história. Movimentos vários a partir de diferentes lugares de enunciação despoletam esta profunda revisão epistemológica do mundo: por um lado, os questionamentos teóricos inerentes à matéria em estudo advindos do mundo europeu e dos pensadores alternativos das suas grandes universidades, por vezes "perdidos" na definição ou redefinição não só do seu objecto de estudo, mas também das fronteiras do seu próprio campo de estudos ${ }^{6}$; por outro lado, os questionamentos vindos da designada periferia, nomeadamente da América Latina, da Índia e da África, ou seja, do que hoje, à falta de melhor expressão, designámos por Sul Global. Mas se em África os movimentos de intelectuais se congregavam à volta das lutas pela libertação do jugo colonial rumo a uma descolonização política, e se a Índia, a partir do grupo dos Subaltern Studies, visava o questionamento da colonialidade do poder, os movimentos sociais e culturais da América Latina discutiam intensamente a sua identidade e pugnavam pela sua "independência cultural", para

5 ZILBERMAN, Regina. "Discursos e Marginalidade", Banco de Dados Literários, org. César Giusti. Catalogação: BDL: CUL-4-008.

6 Refiro-me aqui muito especificamente aos designados Estudos Culturais e toda a polémica envolvente, que não interessa aqui desenvolver. Sobre esta questão ver RIBEIRO, António Sousa e Ramalho, Maria Irene. "Dos estudos literários aos estudos culturais", Revista Crítica de Ciências Sociais, 52-53, 1998. 
utilizar a expressão de Silviano Santiago no seu importante título, Uma Literatura nos Trópicos - ensaios para uma independência cultural. A urgência de escrever a história dos excluídos da grande narrativa do Ocidente - aqui entendidos como sujeitos subalternos, ex-colonizados - e de analisar criticamente a historiografia influenciada pelo colonialismo converteu-se no dado intelectual de luta por uma descolonização global: uma descolonização política, do saber e do poder em todo o mundo, como muito bem mostra Shelley Walia, em Edward Saidy la Historiografia (2004). Tratar-se-ia assim de conceber os estudos pós-coloniais como o grande desafio das novas modernidades emergentes - como defende o antropólogo Don Robotham ${ }^{7}$-, ideia aliás confirmada por aquilo que se poderia chamar o segundo passo político - com grande visibilidade pública - do mundo pós-colonial: o momento em que o Ocidente quis comemorar Colombo e os cinco séculos da sua descoberta da América e a América quis "matar Colombo", não apenas pela mão daqueles que a chegada de Colombo exterminou, mas também por aqueles que a aventura de Colombo transladou da Europa para o Novo Mundo, afinal os "filhos de Colombo", que aí, reterritorializados, "inventaram um outro Ocidente", para utilizar as palavras de Eduardo Lourenço. Nesse momento, e continuando com Eduardo Lourenço, o continente descoberto por Colombo "reescreve a sua própria história e remete-a para a hora-zero de uma "outra história". Não se trata, portanto, do fim da História, mas de uma mudança da ordem da História a partir de múltiplos lugares e sujeitos e do fim, sim, do Ocidente como mito, ou seja, como a luz do mundo que julgava ser quando chegou às terras de Porto Seguro ${ }^{8}$. Mas não se trata também da história narrada pelo índio, o verdadeiro vencido da acção colonizadora instituída pela chegada da Europa ao Novo Mundo, mas da de um "ex-europeu perdido na sua Descoberta", que precisa da morte de Colombo para poder "crer que o Paraíso é mesmo nessa América onde aportou para fugir do Velho Mundo" " E, por isso, como bem adverte Roberto Morales, precisamos reflectir sobre se somos todos

7 Don Robotham, "El poscolonialismo el desafío de las nuevas modernidades". Disponível em: <http://www.cesc.cl/pdf/centrodedocumentacion/GLOBALIZACION-HIBRIDACION-POSCOLONIALISMO/ELPOSCOLONIALISMOELDESAFIODELASNUEVASMODERNIDADES.pdf $>$. Acedido a 15 de agosto de 2007.

8 LOURENÇO, Eduardo. A Morte de Colombo - metamorfose e fim do Ocidente como mito, Lisboa, Gradiva, p. 16.

9 Idem, ibidem, p. 27. 
pós-coloniais e em que sentido ou sentidos diferentes o somos ${ }^{10}$. As vozes da subalternidade índia e negra, involuntariamente transladada para o Novo Mundo, talvez não precisem enterrar Colombo, mas apenas se fazer ouvir, inscritas que estão numa união de vozes de um subalterno Atlântico Sul que se une à dorida e dolorosa África em luta contra todas as formas de colonização de que é vítima, e cujos sujeitos não podem matar o pai, orfãos que foram de uma Europa colonizadora e hoje de um pós-colonialismo, também ele orfão, da Guerra Fria. Não se tratava portanto de defender a ideia cara a alguns teóricos do pós-colonialismo, de que os subalternos não falavam ou não podiam falar. Como defende Laura Padilha, eles sempre falaram ${ }^{11}$, nunca foram ouvidos, o que é substancialmente diferente. Tratava-se antes e portanto de um historicamente longo e profundo momento de surdez do Ocidente, que só quando viu o seu Colombo morto nas mesmas praias onde havia cinco séculos aportara em ritmo de Descoberta, percebeu que havia outros actores desta história aparentemente comum, mas de memórias tão diferentes. Não o aceitar seria o mesmo que dizer que, na história do mundo, as mulheres - subalternas de qualquer sociedade humana, em qualquer momento histórico - nunca falaram. Elas sempre falaram e continuam a falar, apesar dos muitos silêncios promovidos e política e socialmente motivados, dos muitos silêncios que as cobriam e cobrem e de uma surdez quase ontológica que parece mover o mundo de feição patriarcal que nos domina.

Depois de abrir esta caixa poliédrica que o tema deste número me suscitou é este caminho que escolho: o da exclusão das mulheres da história e da literatura, a partir da literatura portuguesa e da história dos impérios reais e imaginados que Portugal masculinamente construiu, invisibilizando as mulheres, não vendo como elas sempre lá estiveram, mas raramente foram vistas, quanto mais ouvidas, como aliás ainda hoje, apesar das sucessivas lógicas de libertação que foram invadindo as mentalidades do país, seja pela via das por-

10 MORALES, Roberto. "Modernidade periférica e mestizaxe diferencial en America Latina”, Tempo Exterior, Instituto Galego de Análise e Documentacíon Internacional. Disponível em: <http://www.igadi.org/te/pdf/te_se13/te25_13_131mario_roberto_morales.pdf >. Acedido a 15 de agosto de 2007.

11 PADILHA, Laura. "A África e as Américas: fluxos e refluxos", conferência proferida no âmbito do Programa de Doutoramento Pós-Colonialismos e Cidadania Global, do Centro de Estudos Sociais da Faculdade de Economia da Universidade de Coimbra, em 21 de junho de 2007. 
tas que Abril abriu a um país que, nos anos 1970, parecia fora da história da Europa e do mundo, seja pelas portas que essa Europa, a partir de meados dos anos 1980, também abriu, marcando o ritmo do país na sua pós-modernidade tardia e praticamente coincidente com a sua pós-colonialidade.

\section{II - Breve narrativa de uma exclusão com a espessura de séculos}

Na epopeia camoniana os versos que precedem a célebre fala do Velho do Restelo falam das "mães, das esposas e das irmãs", cujas lágrimas banhavam a areia branca da praia de embarque. Ao expor os lamentos e as dúvidas expressas pelas esposas e pela universal figura da mater dolorosa, Camões introduz, pela via feminina, o tom de disforia na epopeia hegemonicamente masculina que são Os Lusíadas. Desta forma, ao mesmo tempo que o poeta sensibiliza o seu leitor para o sofrimento envolvido na gesta dos Descobrimentos, enaltece-os não somente enquanto aventura masculina de partida, mas também enquanto aventura feminina das mulheres que ficavam e que, pela via do amor, questionavam a partida dos futuros heróis do mar.

As mulheres cum choro piadoso,

Os homens com suspiros que arrancavam.

Mães, Esposas, Irmãs, que o temeroso

Amor mais desconfia, acrescentavam

A desesperação e frio medo

De já nos não tornar a ver tão cedo.

[...]

Porque is aventurar ao mar iroso

Essa vida que é minha e não vossa?

Como por um caminho duvidoso,

Vos esquece a afeição tão doce nossa?

Nosso amor, nosso vão contentamento,

Quereis que com as velas leve o vento?"[...]

"Nós outros, sem a vista alevantarmos

Nem a mãe, nem a esposa, neste estado,

Por nos não magoarmos ou mudarmos 
Do propósito firme começado,

Determinei de assi nos embarcarmos,

Sem o despedimento costumado,

Que, posto que é de amor usança boa

A quem se aparta, ou fica, mais magoa.

(CAMÕES, 1992: 117-118)

Mas ao colocar este questionamento feminino sobre a gesta marítima no domínio privado das relações familiares e do amor e não no domínio público e político, como acontece com o questionamento elaborado pelo Velho do Restelo, Camões definia os papéis a desempenhar por cada sexo na construção da nação a vir: os homens empreenderiam a viagem que os levaria às futuras terras do império, as mulheres ficariam em casa, aguardando, apoiando e assegurando a vida familiar. Viajar, construir, guerrear e governar contra ficar, assistir, acompanhar, amar - seriam estes os papéis dos dois sexos na construção da nação e do império. E o império se cumpriu pela via masculina, invisibilizando as mulheres. Teríamos de esperar cinco séculos para que estudos, ficções, filmes e séries televisivas começassem a revelar o rosto feminino da expansão, pois sabemos que desde cedo elas viajaram nas carreiras marítimas. Charles Boxer, no seu pioneiro estudo sobre as mulheres na expansão ibérica, revela-nos a sua insidiosa presença nas naus rumo ao Oriente, bem como o importante estudo de Timothy Coates, que conjuga dois elementos periféricos, mas na realidade fundamentais no desenvolvimento dos impérios: degredados e orfãs. Filhas da baixa nobreza e normalmente residentes em instituições estatais e religiosas, estas mulheres eram posteriormente enviadas para as terras da Índia ou do Brasil para se casarem com homens nascidos em Portugal. A Coroa atribuía-lhes um dote que podia ser dinheiro, terras ou cargos burocráticos e, através da esperada descendência resultante desses casamentos, garantia uma presença a longo prazo e, portanto, uma efectiva colonização gerada por elementos originalmente metropolitanos. Outro grupo socialmente problemático, mas também fundamental na colonização, foram as prostitutas, que eram estimuladas a mudar de vida e a embarcar para Angola, para os "Rios de Sofala" ou para o Brasil. Vistas como ventres produtivos da elite colonial por em si conterem a pele branca, e apoiadas pelas instituições religiosas de caridade, que por sua vez se espalhavam por todo o impé- 
rio, estas mulheres - orfãs e prostitutas - foram as primeiras colonizadoras apoiadas pelo Estado e muito contribuíram para o sedimentar da colonização portuguesa. A par dessa narrativa feminina civil do império, a que só muito recentemente foi atribuído valor histórico e portanto público, há aquela que foi protagonizada pelas mulheres missionárias, que, por sua vez, constituíram uma importante base de apoio dos percursos imperiais femininos acima mencionados, e que até ao final do império tiveram um relevante papel, não só na sua relação com os colonos, mas também com as populações locais ${ }^{12}$. $\mathrm{Na}$ instituição religiosa elas estão também no fundo da lista dos nomeados.

Em meados do século XX, e pela voz da poeta são-tomense Alda do Espírito Santo, a denúncia relativa ao papel da mulher africana no sistema colonial é evidente, e a poeta solidariza-se com as suas irmãs de sexo, de dor e de pele:

[...] sigo passo a passo a mulher de pele bronzeada - que é a minha história, das avós dos meus avós e da geração futura [...]

[a mulher é] a última que é a última entre os negros que já são últimos na concepção dos demais povos da categoria civilizada [...] A sua voz não se levanta. Morre na distância. Ela nem voz tem. É escrava. - É mulher negra [...] é vítima de todos. (ESPÍRITO SANTO, 1949: 13-15)

Em língua portuguesa, na então metrópole ou no império, elas estão no fim da lista, fora da história pública protagonizada pelos homens, como aliás fica bibliograficamente confirmado por Maria Regina Tavares da Silva, em $A$ Mulher - Bibliografia Anotada 1598-1998.

Esperámos cinco séculos para que as mulheres que ficaram na praia de embarque escrevessem as suas cartas de volta. Falo das Novas Cartas Portuguesas, escritas a seis mãos por Maria Isabel Barreno, Maria Teresa Horta e Maria Velho da Costa, nos anos 1970, na plena agonia do império e em plena época da emancipação da mulher nas sociedades ocidentais. Utilizando a forma epistolar que favorece o discurso íntimo, mas subvertendo-o ao denunciar as condições de clausura e isolamento em que estava a ser produzido, estas cartas denunciam a discriminação visível em que as mulheres se encontravam, não só numa dimen-

12 Cf. a título de exemplo RIBEIRO, Jorge. Marcas da Guerra Colonial, Porto: Campo das Letras, 1999, os capítulos dedicados às mulheres. 
são espacial - expressa na metáfora do convento, que era o Portugal salazarista/ marcelista - mas também na sua amplitude temporal, ao fazerem eco das Cartas Portuguesas, de Mariana Alcoforado, publicadas em Paris, em 1669, sob o título de Lettres Portugaises. Tratava-se de cartas de amor de uma freira do século XVII que, da clausura do convento, escrevia apaixonadamente ao seu amante, um cavaleiro francês, e que ficaram registadas no imaginário literário português como um pioneiro pronunciamento da palavra escrita feminina. Servindo-se de todos estes ecos, que conferem à discriminação denunciada a espessura de séculos, as Novas Cartas Portuguesas mostram sobretudo a condição das mulheres nesses anos 1970, anos de libertação por toda a Europa e de clausura em Portugal, a braços com uma ditadura agonizante e com uma Guerra Colonial espalhada em três frentes africanas e completamente fora do tempo. Por isso, as autoras de Novas Cartas Portuguesas não utilizam apenas o eco da voz libertária e apaixonada de Mariana Alcoforado, mas todo o contexto histórico das lutas do cavaleiro francês de Mariana ao lado dos portugueses contra o domínio espanhol, lutas essas que espelham bem uma África em luta pela libertação contra o imperialismo português. A tristeza da jovem abandonada pelo namorado que emigrou para a França para não se alistar, a "Carta de um soldado chamado António para uma rapariga chamada Maria a servir em Lisboa", relatando a sua solidão em busca de uma madrinha de guerra, o desabafo de uma mulher desesperada com a violência que o marido lhe inflige desde que retornou da África, o medo de uma mãe de que seu filho vá e não volte, são formas de denúncia da agonia dos heróis do mar cantados por Camões, então em luta em terras africanas, e de compromisso político das autoras, com uma história e com um momento político que estava a ser escrito por homens e por mulheres, que se queriam invisíveis, mas requeridas na "moldura": mulheres-mães, mulheres-esposas, mulheres-noivas, mulheres-irmãs, assistindo, acompanhando, amando.

Utilizando assim os mecanismos e enquadramentos esperados - a partir da margem, da clausura do convento, na intimidade gerada pelo espaço privado da carta - mas denunciando-os com a diferença intrínseca ao discurso veiculado e politicamente motivado, as três Marias retiravam do silêncio oficialmente promovido as lutas em África e o império, a sua condição de mulheres e as desigualdades que sofriam, e denunciavam a sociedade portuguesa como uma sociedade que discriminava, julgava, marginalizava e excluía catalogando, fichando, arquivando, insultando. Daí que as autoras façam não só um trabalho 
de escavação arqueológica, com vista a encontrar ao longo da história o rosto feminino da discriminação, mas também se unam aos seus pares em luta, que tomavam a forma de "Outro", que podia ser "preto", "vermelho" ou de "forma feminina", mas seguramente em "pacto com o Diabo", "por ter ameaçado a ordem superiormente estabelecida" (BARRENO; COSTA; HORTA, 1974: 102-103). No entanto, e como a história sucintamente resumida atrás lhes mostrava, havia diferentes escalões de respeitabilidade da discriminação por parte dessa tal "ordem superiormente estabelecida", escalões de respeitabilidade proporcionais ao impacto que a sua revolta traria ao status quo:

...lembremo-nos, sim, que um negro extremista é já respeitável, mas que uma feminista é vituperada, assustadora do ainda indiscutível, incómoda, ridícula, mesmo para os cavaleiros bem pensantes de toda a libertação [...] Quando o burguês se revolta contra o rei, ou quando o colono se revolta contra o império, é apenas um chefe ou um governo que eles atacam, todo o resto fica intacto, os seus negócios, as suas propriedades, as suas famílias, os seus lugares entre amigos e conhecidos, os seus prazeres.

Se a mulher se revolta contra o homem nada fica intacto.

(BARRENO; COSTA; HORTA, 1974: 108-175)

Daí que, e seguindo a lógica de um texto feminista que tem como subtexto o problema africano, a pergunta seja imediata pela conjugação das duas discriminações que sobre a mulher se abatem e que assim se denunciam: Será então a mulher "a última colónia do homem?" (idem, p. 285).

Apreendido em 1972 aquando da sua publicação, não só pelas diabrites feministas que continham, e como foi argumentado pela censura, mas pela forma como atingiam a própria masculinidade dos homens, ao denunciarem o estado em que eles vinham de África e ao darem opinião sobre um problema político e portanto do domínio masculino e público, as autoras de Novas Cartas Portuguesas, brincando, como era próprio da sua "condição de fêmea" na visão masculina (idem, p. 153), mas brincando de forma "conscientemente assumida" (PINTASILGO, 1980: 21), lançavam subversivamente um questionamento avassalador. Um questionamento que iria do privado - a casa, a família e o corpo - ao público - incluindo a nação, a sociedade, os valores políticos, éticos e morais. E, como se questiona em Novas Cartas em relação à suposta "clausura" 
de Mariana, "Com que cara fica um convento onde uma freira escreve cartas de amor, atestando a falência de uma clausura onde entram e saem cavaleiros franceses?" (BARRENO; COSTA; HORTA, 1974: 33). Jogando, como se joga em Novas Cartas, poderíamos ainda perguntar: como fica a "casa portuguesa" em que a mulher sai em busca da sua identidade própria, que passará pela libertação mental e corporal e pelo questionamento da sua função social e familiar? E poderíamos ainda continuar o jogo e reciclar a questão, perguntando: como fica a casa imperial portuguesa, quando a mulher, suposto invisível sustentáculo desta extensão de acordo com a ideologia da família salazarista, também sai, passando a sua busca identitária sobretudo pela libertação?

Parece assim ser também delas a mão que levanta o véu, não só em Portugal metropolitano, mas também nas então colónias onde decorria a guerra, levandonos a pensar que o grito de libertação que de lá vinha pela mão dos nacionalistas africanos, se espalhava com diferentes propósitos e diferentes agendas por uma série de margens que a partir dos anos 1960 se foram erguendo e de que as mulheres não eram apenas mais uma parte. Não era só a sedimentação da colonização que falhava, nem a guerra nos seus aspectos bélicos não pronunciados que não cumpria os seus objectivos, nem a ditadura que se esvaziava. Era de facto uma estrutura e um país que ruíam e em que nada parecia ir ficar "intacto".

\section{III - O tempo dos pós e dos nossos eufemismos para designar velhas exclusões}

Com o 25 de Abril de 1974 findava o Portugal imperial de cinco séculos de existência real e imaginada, e, particularmente, o Portugal colonizador das terras de África, cuja fisionomia começara a desenhar-se no final do século XIX e condicionaria toda a política portuguesa, desde o regicídio à Primeira República, desde o Estado Novo ao seu derrube, após uma longa Guerra Colonial que acabou por conduzir ao 25 de Abril de 1974. Assim, com o 25 de Abril findava também o Portugal anti-democrático e ditatorial que durante 48 anos dominou e, por isso, no caso português, pós-colonialismo está intimamente ligado a pós-salazarismo/caetanismo e, portanto, ao início de uma vivência democrática, de exercício pleno dos direitos de cidadania e de escrita e informação livres. Mercê das mudanças estruturais em todos os sectores da 
sociedade portuguesa e no redesenhar do mapa da nação que o 25 de Abril trouxe, a ficção, o ensaísmo e, mais tardiamente, a historiografia das últimas décadas, têm vindo a reflectir sobre a questão da identidade nacional portuguesa, reconfigurada pela Revolução, com os processos de territorialização - a descolonização das antigas colónias africanas, o regresso de emigrantes e o regresso de exilados - seguidos quase de um processo de desterritoralização, com o início das negociações para a adesão à Comunidade Europeia.

Após o 25 de Abril de 1974, Portugal passou de nação "colonizadora por excelência a nação criadora de nações" (LOURENÇO, 1983: 20), havendo neste parto, já não definido como tal, o fundamento de redenção necessário à sua jovem democracia. Nesta linha, a entrada de Portugal para a Europa comunitária, ainda que num primeiro momento possa ser vista como um volte-face necessário para rapidamente aliviar Portugal de traumas imperiais e neutralizar vagos sonhos de reencontro de uma geografia afectiva e cultural portuguesa inscrita na imagem do antigo império, foi também a maneira politicamente conseguida de rapidamente colocar Portugal num tempo pós-colonial, integrando-o de imediato na família das antigas metrópoles coloniais, agora nações pós-coloniais, à qual Portugal chegava já em plena pós-modernidade. Mas não era só Portugal que, libertando-se das ruínas e dos fantasmas do império, ia até à Europa. Era também a Europa que viria até Portugal - "A Europa connosco", no conhecido slogan da época - e que, ao inverter o sentido da busca há séculos feita da periferia para o centro, sentava Portugal confortavelmente na mesa das nações europeias, dando-lhe a possibilidade de se imaginar como um país europeu. Como sublinha Eduardo Lourenço e, mais tarde, Sousa Santos, no slogan acima citado estava contida a promessa de que Portugal poderia tornar-se uma sociedade democrática como as da Europa Ocidental, dissipando-se deste modo os receios, dos sectores mais conservadores da esquerda e da direita, de que Portugal desapareceria submerso às vontades das grandes potências europeias, assumindo-se portanto que "estar com a Europa é ser como a Europa" (SANTOS, 1996: 58).

Este era o colorido cenário da "tensão fundadora"13 da jovem democracia portuguesa iniciada pelo acto político do 25 de Abril. Mas isto, obvia-

13 A expressão é de Michel Cahen, "Des caravelles pour le futur? Discours politique et idéologie dans l' institutionnalisation de la Communauté des Pays de Langue Portugaise", Lusotopie, 1997, p. 391-433. 
mente, não significa que com o 25 de Abril findavam os problemas que o salazarismo/marcelismo tinha deixado por resolver. Pelo contrário, o 25 de Abril resulta em grande parte da procura de soluções alternativas à hesitação e impasse que caracterizaram a ditadura de Marcelo Caetano. Por isso, ao mesmo tempo em que existem rupturas claras de política e pensamento, também existe uma certa continuidade, dada por hábitos que se mantêm, personalidades que se transferem e, de forma diferente, mas paradoxalmente semelhante ao anterior regime, a mesma impossibilidade de encontrar a resposta política rápida e eficaz para todas as questões: questões que se ligam não só aos problemas de territorialização e desterritorialização, mas também à justiça social, ao ensino e, genericamente, a todos os sectores da vida pública, o que levou a um alargamento exponencial do imaginário de libertação política do MFA para um imaginário político e "social de libertação, no centro de um universo simbólico de luta contra a miséria e injustiça" (SANTOS, 1985: 47). Nesta avalanche de reivindicações e de lutas, onde ficaram as lutas pela emancipação feminina, onde ficaram as mulheres? Dado o ponto de partida poderíamos, simpática e muito masculinamente, dizer que uma das principais conquistas de Abril foi a libertação da mulher. E terá sido, sem dúvida, em face da impensável situação de subordinação em que à data se encontravam. Mas foi pela pressão que elas próprias exerceram, pela força política e cultural dos seus actos nas fábricas, nas instituições, nos jornais, nas universidades, lançando os primeiros trabalhos académicos sobre o tema na década de 1980, na vida política e cultural, pela sua inscrição própria na história através de ficções, pinturas ou esculturas, que esse lugar foi conquistado.

Hoje, mais de trinta anos depois do 25 de Abril, verificamos que tivemos praticamente de esperar vinte anos para começar a ver reconhecido, através de estudos académicos, o papel das mulheres na história de Portugal - seja na história mais remota, nomeadamente na época considerada pelos portugueses como áurea, ou seja, a época da expansão ${ }^{14}$, seja na história recente, nomeadamente com os estudos sobre as mulheres durante o fascismo e a

14 Cf. por exemplo os ensaios publicados nas actas do Congresso Internacional O Rosto Feminino da Expansão Portuguesa: actas I e II, Cadernos Condição Feminina, 43, Lisboa: Comissão para a Igualdade e para os Direitos da Mulher, 1995, e a revista Oceanos, "Mulheres do Mar Salgado", 21, jan./fev. 1995. 
resistência ao fascismo ${ }^{15}$-, o seu estudo específico através de cursos de pósgraduações de estudos de mulheres ou de estudos feministas, a sua efectiva igualdade perante a $\mathrm{lei}^{16}$... mas todos nós recordamos facilmente a notícia da primeira mulher juíza ou da primeira mulher reitora de uma universidade portuguesa? Hoje, rigorosamente em 2007, mais de trinta anos depois do 25 de Abril, e quase dez anos após o malogrado referendum de 1998 sobre a interrupção voluntária da gravidez, as mulheres portuguesas vêem reconhecido o seu direito legal ao aborto, ainda que, e apesar da legislação nacional, a região autónoma da Madeira insista em não aplicar a lei da República, não permitindo a criação das condições logísticas para a sua aplicabilidade.

As lutas das mulheres e a sua emancipação no pós-25 de Abril sofrem, no fundo, do mesmo "mascaramento"17 que a memória histórica portuguesa, mais amiga do mito do que da história. Assim, da mesma maneira que após o 25 de Abril se classificou o golpe como pacífico e a "Revolução sem sangue", esquecendo todo o sangue de África que ela em si trazia, ou o PREC como um tempo em que "mesmo com uns erros pelo meio, não houve violência nem guerra", esquecendo os actos violentos que também fizeram parte do PREC, também a ditadura passou da memória à história para a segunda geração como mais ou menos meiga, Salazar como um ditador provinciano, mas pacato, a PIDE como uma polícia política que "não era tão má como as outras", o sistema colonial português como mais brando do que os outros, como se houvesse colonialismos bons e maus, a Guerra Colonial como uma "guerra de brincadeiras", porque guerra a sério foi a do Vietname que vi-

15 Cf. por exemplo Vanda Gorjão, Mulheres em tempos sombrios - a oposição feminina ao Estado Novo, Lisboa: ICS, 2002; Ana Barradas, As clandestinas, Lisboa: Ela por Ela, 2004; Irene Flunser Pimentel, História das organizações femininas no Estado Novo, Lisboa: Círculo de Leitores, 2000; Sílvia Espírito Santo, Adeus, até ao teu regresso - o Movimento Nacional Feminino na Guerra Colonial (1961-1974), Lisboa: Livros Horizonte, 2003; As mulheres e a Guerra Colonial, número temático da Revista Crítica de Ciências Sociais, 68, abril, 2004; Margarida Calafate Ribeiro, África no feminino - as mulheres portuguesas e a Guerra Colonial, Porto: Afrontamento, 2007. 16 Sobre a subalternização da mulher portuguesa em face da lei durante a ditadura ver Manuela Tavares, Movimentos de Mulheres em Portugal - Décadas de 70 e 80, Lisboa: Horizonte, 2000.

17 Cf. a seguinte declaração de Maria de Lourdes Pintasilgo: "Houve uma grande presença de mulheres e um grande entusiasmo; mas veio a acontecer como noutras revoluções: as mulheres que são protagonistas num primeiro momento, depois são silenciadas, pela calma que segue à revolução. Rapidamente se tornam invisíveis; temos a sensação que regressaram a casa, mas continuam de facto a lutar", in Manuela Tavares, Movimentos de Mulheres em Portugal-Décadas de 70 e 80, Lisboa: Horizonte, 2000, p 27. 
mos nos filmes ${ }^{18}$, e o mito do português não racista e cordial continuou nos tempos pós-lusotropicais ${ }^{19}$ que vivemos. E todos colaborámos para que esta pós-memória da ditadura se construísse: pais, manuais escolares e portanto sistema educativo estatal, historiografia, que até hoje recusa uma abordagem pós-colonial, jornalistas, políticos, particularmente nas políticas de cooperação ou europeias, cujos preâmbulos legislativos ou discursos recuperam invariavelmente uma mitologia fraseológica conhecida e previsível ${ }^{20}$. O velho mito dos "brandos costumes portugueses", corolário de todo este manto mitológico sobre a história, mantém-se e prolifera e, portanto, voltando à questão da emancipação das mulheres, ela só poderia ser também uma "emancipação mascarada", como disse, em bom abono da verdade, Maria de Lourdes Pintasilgo (1980, p. 21), não por acaso a primeira e única mulher portuguesa que atingiu o cargo de primeira-ministra. ${ }^{21}$

Hoje continuamos com as falsas verdades: as mulheres portuguesas estão em pleno no mercado de trabalho, são a maioria nas universidades, já há mais

18 Sobre a pós-memória da ditadura ver o estudo de Tiago Matos Silva, "O 25 de Abril tal como é ensinado - a democracia e o ensino da História", in Manuel Loff e M. Conceição Meireles Pereira (coordenadores), Portugal: 30 Anos de Democracia (1974-2004), Actas do colóquio realizado na Faculdade de Letras da Universidade do Porto, Porto: Universidade do Porto, 2006, p. 251-263, de onde retirei alguns destes dados.

19 A expressão é de Miguel Vale de Almeida, Um mar da cor da terra - raça, cultura e política da identidade, Oeiras: Celta, 2001.

20 Cf. a título de exemplo excertos do preâmbulo do despacho normativo do Ministério da Educação que criou o programa inter-escolas "Entre Culturas", de 1991: "A cultura portuguesa, marcada por um universalismo procurado e consciente e pelos múltiplos encontros civilizacionais que, ao longo dos séculos, têm permitido o acolhimento do diverso, a compreensão do outro diferente, o universal abraço do particular, é uma cultura aberta e mestiçada, enriquecida pela deambulação de um povo empenhado na procura além-fronteiras da sua dimensão integral. [...] Cumprida uma fascinante peregrinação de séculos, Portugal retorna ao seio do continente europeu e integra-se no seu espaço cultural de origem, contribuindo, com a mundividência que o caracteriza, para a efectiva construção de uma Europa aberta, solidária e ecuménica". (Despacho Normativo n. 63/91, Ministério da Educação)

21 Não esqueçamos que um dos primeiros actos censórios do pós-25 de Abril recaiu sobre um programa de Maria Antónia Palla e Antónia de Sousa, exibido desde agosto de 1974 sob o título Nome - Mulher, que na edição de maio de 1976 emitiu uma reportagem sobre o aborto. Seguiram-se protestos de três partidos políticos - PDC, CDS e PPD - e da Ordem dos Médicos. O programa foi suspenso e a jornalista responsável processada por atentado ao pudor e incitamento ao crime, acabando por ser absolvida em maio de 1979. A contra-reacção a esta atitude censória levou a actos políticos de protesto e afirmação e desencadeou uma série de lutas pela legalização do aborto, que só em 2007 foi legalizado em Portugal. Sobre isto ver Manuela Tavares, Movimentos de mulheres em Portugal - décadas de 70 e 80, Lisboa: Horizonte, 2000, p. 45-51, e Andrea Peniche, Elas somos nós - o direito ao aborto como reivindicașão democrática e cidada, Porto: Afrontamento, 2007. 
médicas do que médicos, esquecendo que elas são as mais vulneráveis no mercado de trabalho, as que em alguns empregos ainda usufruem de menor salário pelo mesmo trabalho. Portanto, na mesma lógica, tudo está no bom caminho, e o que não está, está de acordo com a Europa. Consultando Um guia para as jovens mulheres sobre a igualdade de oportunidades na Europa, as diferenças entre os dois sexos nos países da União Europeia são bem visíveis, para além ainda das enormes discrepâncias que existem entre os vários países membros. Os números da União Europeia como um todo falam por si:

- A taxa de emprego das mulheres é de 51,2\%, enquanto a dos homens é de $70,8 \%$.

- A taxa de emprego das mulheres com pelo menos um filho é de 51,2\%, a das mulheres sem filhos é de $68 \%$.

- 83\% do trabalho part-time é executado por mulheres.

- 41\% das mulheres executivas não têm filhos, mas a maioria dos homens em posições equivalentes têm; 90,8\% destas mulheres afirmam que não têm possibilidades de interromper a carreira.

- 9 em cada 10 famílias monoparentais são encabeçadas por uma mulher. $^{22}$

Escolhi estes indicadores não só para mostrar a situação das mulheres que numa primeira análise eles ilustram, mas sobretudo para mostrar (como os dados claramente indicam) que a questão não é, como seria privada e publicamente cómodo de ver, um problema das mulheres. É um problema das famílias, é uma questão nacional e europeia, do ponto de vista social e político, e portanto deve ter respostas políticas. Continuar, com sábia habilidade política, a relegar para a esfera das mulheres e dos problemas de mulheres este tipo de dados e respectivas análises é permitir uma política irresponsável em termos sociais e éticos contemporâneos e é prolongar uma política de séculos de exclusão, de injustiça social e cognitiva.

Mercê das grandes modificações sociais e laborais do último século e de uma afirmação cada vez mais contínua e acelerada das mulheres no domínio público, muita coisa tem vindo a ser feita, mas ainda demorará muito para que

22 Um Guia para as jovens mulheres sobre a igualdade de oportunidades na Europa, disponível na internet em $<$ http://www.afem-europa.org/downloads/Portugal-guide-jeunes-portugais.PDF $>$, versão portuguesa de 2001. Acedido em 12 de outubro de 2006. 
se perceba o universo simbólico subjacente aos mitos, aos hábitos, às memórias. Nas margens dos discursos homocêntricos, por natureza absurdamente autocentrados e narcísicos, existiram sempre outras versões, a evidenciarem a existência de diferentes sujeitos sociais, históricos e culturais, que regras, hábitos, preconceitos, mas também políticas, religiões e legislações se encarregaram de invisibilizar e silenciar. Essa diferença fundadora de existência e de direito de existência impede muitas vezes o estabelecimento de conexões entre duas formas diferentes de estar no mundo, de o organizar, de o narrar e historicizar ${ }^{23}$. Visões da vida e da história diferentes, como teve Paula Rego olhando a história narrada numa peça pictórica clássica do colonialismo português/brasileiro - A Primeira Missa, de Vitor Meirelles, de 1860.

Em 1993, Paula Rego traça outra "A Primeira Missa no Brasil"24, colocando nela um dos mais pujantes desafios aos estudos feministas e à historiografia portuguesa tão pouco pós-colonial, tão pouco feminista. Sobre A Primeira Missa, de Vitor Meirelles, que narra a chegada dos "Colombos" ao Novo Mundo, Paula Rego coloca, em primeiro plano, o corpo de uma mulher grávida, deitada numa cama de grades, com a cabeça sobre a camiseta de um marinheiro, convidando-nos assim a uma outra leitura da história das colonizações. A aproximação simbólica entre a violação e a colonização da terra brasileira, e a violação e colonização de um corpo feminino, como sugerido por Memory Holloway ${ }^{25}$, aproxima esse quadro da posição narrativa expressa em Novas Cartas Portuguesas da mulher como a "última colónia do homem", num sentido físico, mental e espiritual. Paralelamente, a outra história de colonização que esse quadro também está a narrar não é pós-colonialmente a dos índios, que Vitor Meirelles integrou na paisagem, tornando-os assim historicamente invisíveis na gesta colonizadora que o quadro celebra. A história da colonização que A Primeira Missa, de Paula Rego, está a narrar é a das

23 Agradeço a Laura Padilha esta reflexão.

24 Sobre este quadro ver Maria Manuel Lisboa, Paula Rego's map of memory. National and sexual politics, Hants: Ashgate, 2003; Francisco Bethencourt, "Desconstrução da memória imperial: literatura, arte e historiografia", in Margarida Calafate Ribeiro e Ana Paula Ferreira, Fantasmas e Fantasias Imperiais no Imaginário Português Contemporâneo, Porto: Campo das Letras, 2003, p. 69-89.

25 Memory Holloway, "Effet de miroir; regard vers le passé, marche vers l'avenir", in Secrets Dévoillés. Dessins et gravures de Paula Rego, Paris: Centre Culturel Calouste Gulbenkian, 1999, p. 7-25; "Praying in the sand: Paula Rego and the visual representations of the first mass in Brazil", Portuguese Literary and Cultural Studies, Spring/ Fall, 2000, p. 697-705. 
"ausências" da história oficial da colonização, e, portanto, não coincide com a narrativa hegemónica, masculina e unilateral representada no quadro que lhe serve de inspiração, onde marinheiros e religiosos afirmam o acto colonial pela imposição dos seus símbolos, do seu poder e dos seus corpos na paisagem. Ao inverter, por meio da primazia dos planos pictóricos, a narrativa histórica hegemónica até aí construída, Paula Rego está a dar voz narrativa àqueles, ou neste caso àquelas, que Marcus Greil chamou "os refugiados da história" (1997, p. 17), aqueles que ficaram sem lugar na história, neste caso específico na narrativa colonial, mesmo quando, como no caso das mulheres, elas foram produtoras - enviadas, forçadas, e raramente amadas - da segunda fase da gesta imperial, ou seja, da colonização propriamente dita, tanto no Portugal europeu, esperando na praia de embarque, como nas terras do então império. Com este quadro, Paula Rego não está a anunciar as previsíveis comemorações de Colombo do ano 2000, nem da possível morte de Colombo pela América, na citada interpretação de Eduardo Lourenço, mas tão só a utilizar o eco histórico da colonização que o quadro original evoca, para ao mesmo tempo denunciar a colonização do corpo feminino pela sociedade patriarcal em que vivemos, por sua vez reflectida no não-lugar das mulheres na memória e na história da gesta imperial. Por isso este momento pictórico constituiu uma dupla denúncia, privada e pública, de uma sociedade que nas suas práticas e na sua historiografia discrimina e marginaliza. Por isso, e à semelhança de Novas Cartas Portuguesas, este quadro fala de estruturas sociais e de relações entre dominadores e dominados. Por isso, e à semelhança de Novas Cartas Portuguesas nos anos 1970, o quadro de Paula Rego constitui ainda hoje um pronunciamento e um estímulo para reolhar o cânone narrativo, no sentido lato do termo, e ver de facto tudo o que ele deixou e continua de fora, ou seja, a excluir. A proposta de Paula Rego, como a de Novas Cartas Portuguesas, nos anos 1970, implica não apenas uma mudança do olhar, mas uma mudança da escala do olhar ${ }^{26}$.

26 Expressão retirada de um verso de Fiama Hasse Pais Brandão. 


\section{Referências Bibliográficas}

ALCOFORADO, Mariana. Cartas Portuguesas. Lisboa: Mel, 2003.

BARRENO, Maria Isabel; COSTA, Maria Velho da; HORTA, Maria Teresa. Novas Cartas Portuguesas. Lisboa: Futura, 1974.

BOXER, Charles. A mulher na expansão ultramarina ibérica. Lisboa: Horizonte, 1975.

CAMÕES, Luís de. Os Lusíadas. Lisboa: Instituto Camões, 1992. Canto IV, 91 e 93, p. $117-118$.

CANDIDO, Antonio. Textos e Comentários. São Paulo: FCE, 1995.

COATES, Timothy. Degredados e órfãs: colonização dirigida pela Coroa no império português. 1550-1755. Lisboa: CNCDP/ INCM, 1998.

ESPÍRITO SANTO, Alda do. Luares de África. Mensagem, 1949, n. 7, ano I, p. 13-15. GREIL, Marcus. The Dustbin of History. Londres: Picador, 1997.

LOURENÇO, Eduardo. Crise de identidade ou ressaca imperial. Prelo, n. 1, out./dez. 1983.

PINTASILGO, Maria de Lourdes. Pré-Prefácio e Prefácio. In: BARRENO, Maria Isabel; COSTA, Maria Velho da; HORTA, Maria Teresa. Novas Cartas Portuguesas. Lisboa: Moraes, 1980.

SANTOS, Boaventura de Sousa. Pela mão de Alice - o social e o político na pós-modernidade. Porto: Afrontamento, 1996.

- A crise do Estado e a aliança Povo/MFA em 1974-1975. In: Seminário - 25 de Abril 10 Anos Depois. Lisboa: Fundação Gulkbenkian/Associação 25 de Abril, 1985. 